\title{
FATIGUE PROPERTIES OF WELD JOINTS OF STEEL SHEETS TREATED BY NITROOXIDATION
}

\author{
MICHALEC, I[van]; JANCAR, J[aroslav] \& MARONEK, M[ilan]
}

\begin{abstract}
Nitrooxidation is a method of surface treatment of steels, by which the radical mechanical properties and corrosion resistance can be improved. Previous results were related to the fatigue properties of the steel sheets treated by nitrooxidation. This paper deals with the fatigue properties of the laser beam weld joints of the steel sheets before and after the process of nitrooxidation. The results proved the higher fatigue life of steel sheets after the treatment.
\end{abstract}

Key words: nitrooxidation, laser welding, fatigue properties, $S$ - $N$ diagram

\section{INTRODUCTION}

Nitrooxidation belongs to the non-conventional methods of steel sheets surface treatment, which consists of surface nitridation and post oxidation. By this process, increase of mechanical properties together with the corrosion resistance can be done (Kuníková et al., 2005).

The fatigue of materials is a degradation process of irreversible changes in material's properties. It is caused by the cyclic strain, thermal or thermo-mechanical loading with simultaneous affect of another internal or external factors (Palček et al., 2011).

By previous results (Palček et al., 2011, Marônek et al., 2011), the higher fatigue life was proved in case of non welded steel sheets treated by nitrooxidation. However, this type of treated steels have a great potential in industry, so the fatigue life of the weld joints has to be determined (Kozlík, 2011).

Solid-state laser beam welding was marked as the most suitable welding method (Jančár et al., 2011), that is why it was chosen for welding the test specimens.

\section{MATERIALS AND METHODS}

For experimental activity, low-carbon deep drawing steel sheets DC 01 EN 10130-9 of 1 mm thickness were used. The chemical composition of this steel is documented in Table 1. The materials were put through the nitrooxidation in fluidised bed. The nitridation was carried out in an atmosphere of gaseous ammonia with fluidised bed consisting of $\mathrm{Al}_{2} \mathrm{O}_{3}$ with granularity of $120 \mu \mathrm{m}$. Immediately after the process of nitridation, the oxidation in vapour of distilled water was performed. Process parameters are given in Table 2.

\begin{tabular}{|c|c|c|c|c|c|}
\hline EN Code & $\begin{array}{c}\text { C } \\
{[\%]}\end{array}$ & $\begin{array}{c}\text { Mn } \\
{[\%]}\end{array}$ & $\begin{array}{c}\text { P } \\
{[\%]}\end{array}$ & $\begin{array}{c}\text { S } \\
{[\%]}\end{array}$ & $\begin{array}{c}\text { Si } \\
{[\%]}\end{array}$ \\
\hline DC 01 & 0.12 & 0.60 & 0.045 & 0.045 & 0.1 \\
\hline
\end{tabular}

Tab. 1. Chemical composition of DC 01 steel

\begin{tabular}{|l|c|c|}
\cline { 2 - 3 } \multicolumn{1}{c|}{} & Temperature $\left[{ }^{\circ} \mathrm{C}\right]$ & Time [min.] \\
\hline Nitridation & 580 & 45 \\
\hline Oxidation & 350 & 5 \\
\hline
\end{tabular}

Tab. 2. Parameters of nitrooxidation
Experimets were performed at the Faculty of Mechanical Engineering at the University of Žilina. As a testing equipment, ultrasonic fatigue machine KAUP-ŽU, consisting of piezoceramic transformer, conic stress concentrator, ultrasonic generator and specimen was used. The fatigue experiments were done in condition of bending loads with frequency of $20 \mathrm{kHz}$ oscillation. All specimens were tested to the failure point. The specimens (Fig. 1) were welded on a TruDisk 1000 solid-state laser in PGS Automation, Trnava.

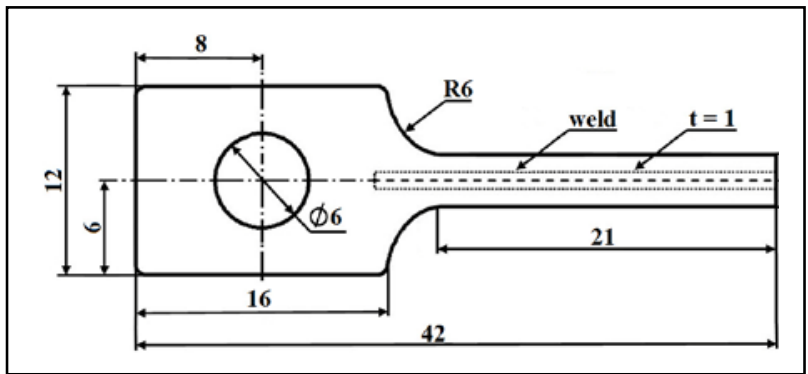

Fig. 1. Testing specimen

The character of the fatigue fracture of the specimens was observed by the electron scanning microscope at the Faculty of Mechanical Engineering at the University of Žilina.

\section{RESULTS}

The results of the fatigue tests are referred in the form of $\mathrm{S}$ $\mathrm{N}$ diagrams, which represents the stress amplitude $\sigma_{\mathrm{a}}$ dependence on the number of cycles to failure. All the measurements were carried out in the interval of the amplitude $\sigma_{\mathrm{a}}=(230 \div 70) \mathrm{MPa}$. The results are documented in Fig. 2. Graph shows the fatigue properties of the weld joints of the material after nitrooxidation in comparison to the not treated material.

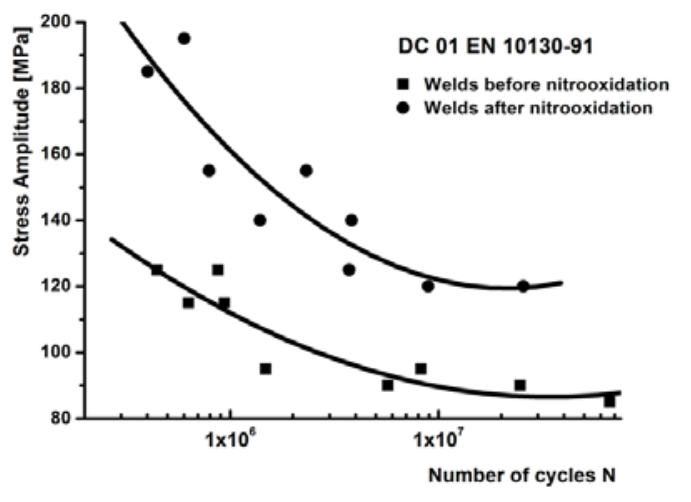

Fig. 2. S - N diagram of the weld joints 
The trend of the curves proved that the fatigue life of the steel sheets treated by nitrooxidation containing welds was higher in comparison to those without surface treatment. The fatigue curves of weld joints before and after nitrooxidation have a similar shape. The higher fluctuation of measured data was observed at samples after surface treatment. This may have been caused by a variable thickness of the surface layer.

The fatigue cracks observed during the fractography analysis had the transgranullar character (Fig. 3.). The fracture areas were characterized by the presence of the striation fields. The final fracture of these specimens was observed either in the middle of the specimen or at the top or at the bottom of the surface. That was in dependence on the area of a major crack initiation and the main fatigue crack propagation.

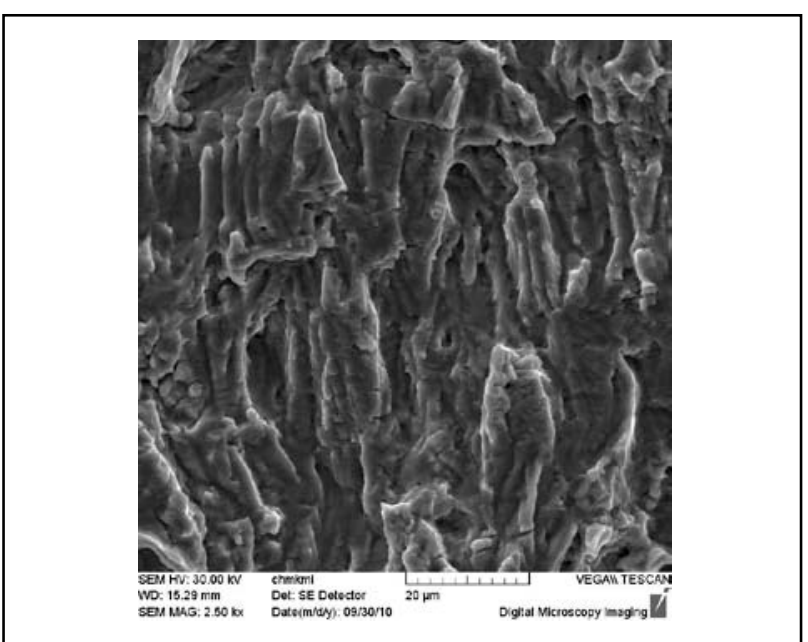

Fig. 3. Transgranullar fatigue crack of the material after nitrooxidation

The fractographic analysis was further oriented on the obtaining the information about surface layer damage and its fatigue behaviour. In case of the treated material, the damage of the surface oxide layer (Fig. 4) at the top of the material was observed both in the fracture initiation as well as the final fracture. The nitride layer was damaged strictly by the ductile type of the fracture (Fig. 5). The individual nitrides could be identified after the etching (Fig. 5).

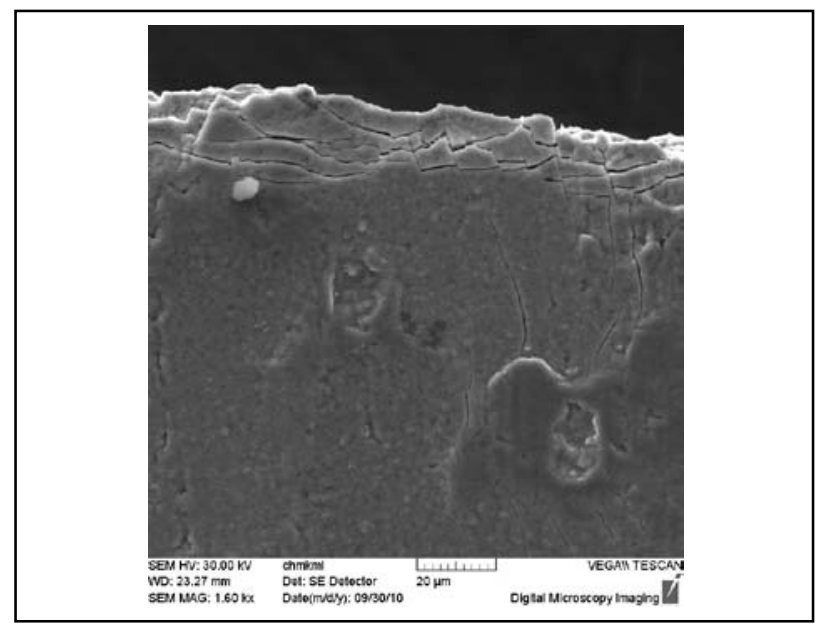

Fig. 4. Damaged oxide layer in the area of crack initiation

Fractography of the non-treated materials showed the fatigue cracks were initiating from both sides of the joints. In case of the nitrooxidized material, the multi-numerous fatigue cracks initiation was observed.

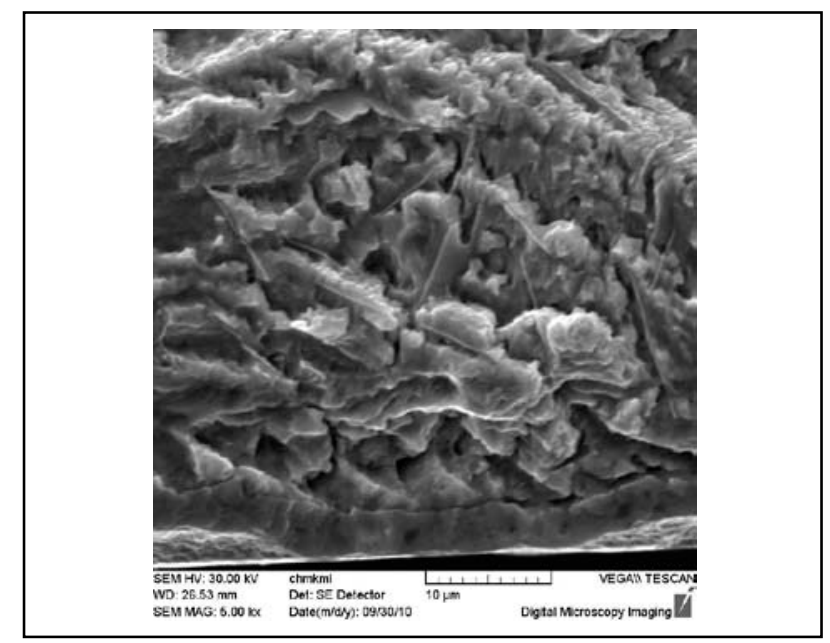

Fig. 5. Close-up view on the oxide layer and coarse-grained needles of nitrides in the area of fatigue crack

\section{CONCLUSION}

Previous outcomes (Palček et al., 2011, Marônek et al., 2011) showed the high fatigue life of nitrooxitized materials. It is an ideal to apply the surface treatment after the welding process. Nevertheless, in some cases it is essential to apply the welding process after the surface treatment. In such cases the solid-state laser beam welding was marked as the most suitable welding method.

Based on the results, it can be stated, that the weld joints treated by nitrooxidation had a higher fatigue life in comparison to weld joints of non-treated material. By this fact, it can be stated, that the process of nitrooxidation has a positive effect on fatigue properties of either the non-welded and welded steel sheets.

The further research activity will be focused on fatigue properties of steel sheets treated by PLASOX ${ }^{\circledR}$ process, which consists of surface plasma nitriding and subsequent post oxidation.

\section{ACKNOWLEDGEMENTS}

This paper was prepared within the support of Slovak Research and Development Agency, grant No. 0057-07 and Scientific Grant Agency VEGA, grant No. 1/0203/11.

\section{REFERENCES}

Palček, P.; Mintách, R.; Nový, F.; Chalupová, M. \& Marônek, M. (2011). Change of fatigue characteristics of deepdrawing sheets by nitrooxidation, Chemické listy, Vol. 105, Issue 16 (2011), pp. 539-541

Marônek, M.; Bárta, J.; Palček, P. \& Ulrich, K. (2011): Fatigue properties of steel sheets treated by nitrooxidation. World Academy of Science, Engineering and Technology, Year 7, Issue 77 (2011), pp. 291-296

Kozlík, P.: The fatigue characteristics of weld joints of steel sheets treated bynitrooxidation. Diploma Thesis (2011)

Jančár, J.; Michalec, I.; Bárta, J. \& Marônek, M. (2011): Laser beam utilisation in welding of steel sheets treated by nitrooxidation. Laser beam utilisation in practice, Plzeň, Czech Republic, 29 - 30 May, 2011, pp. 25-35

Kuníková, T.; Lazar, R.; Dománková, M.; Mošková, L. \& Kamasová-Mareková, Z. (2005): Evaluation of corosion resistance of nitrided and nitrooxidised low-carbon steel. CO-MAT-TECH 2005:Proceedings/ International Scientific Conference, Trnava, Slovak Republic, 20-21 October, 2005, pp. 671-678 